\title{
Cost System Design and Cost Management in the Spanish Public Sector
}

\author{
Llorenç Bagur $^{1}$ \\ Josep Lluis Boned ${ }^{2}$ \\ Mike Tayles ${ }^{3}$
}

\begin{abstract}
Cost systems have been shown to have developed considerably in recent years and activity-based costing (ABC) has been shown to be a contribution to cost management, particularly in service businesses. The public sector is composed to a very great extent of service functions, yet considerably less has been reported of the use of ABC to support cost management in this sector.

In Spain, cost systems are essential for city councils as they are obliged to calculate the cost of the services subject to taxation (eg. waste collection, etc). City councils must have a cost system in place to calculate the cost of services, as they are legally required not to 'profit', from these services.

This paper examines the development of systems to support cost management in the Spanish Public Sector. Through semi-structured interviews with 28 subjects within one City Council it contains a case study of cost management. The paper contains extracts from interviews and a number of factors are identified which contribute to the successful development of the cost management system.

Following the case study a number of other City Councils were identified where activity-based techniques had either failed or stalled. Based on the factors identified in the single case study a further enquiry is reported. The paper includes a summary using statistical analysis which draws attention to change management, funding and political incentives as factors which had an influence on system success or failure.
\end{abstract}

Keywords: cost system, management accounting, activity based costing, public sector.

JEL Classification: M41, M49.

\footnotetext{
${ }^{1}$ Department d'Economia i Empresa, Universitat Pompeu Fabra, Barcelona, SPAIN. llorenc.bagur@upf.edu

${ }^{2}$ Department d’ Economia i Empresa, Universitat Pompeu Fabra, Barcelona, SPAIN. josep.boned@upf.edu

${ }^{3}$ Hull University Business School, Hull, HU6 7RX, UK. m.e.tayles@hull.ac.uk
} 


\section{Introduction}

Activity Based Costing (ABC) and its derivatives have now enjoyed over a decade of high profile. Adoption rates now run over $20 \%$ of large companies in the west. In addition to its application in a wide variety of commercial manufacturing business it has also been adopted by public utilities, by wholesale and retail organisations and by a range of service firms (Innes and Mitchell, 1995, Innes et.al. 2000, Drury and Tayles 2000).

The emergence of ABC has been accompanied by a development phase which has revealed a number of applications which extend beyond merely costing to several important aspects of cost management (ABCM, ABM). Indeed, this breadth of application and the considerable benefits which it continues to promise justifies the prediction made some time ago:

'...(ABC) certainly ranks as one of the two or three most important management accounting innovations of the twentieth century'. (Johnson, 1990)

But also that:

‘a juggernaut is loose in the business world’ (Johnson 1992)

It has been shown that ABCM /ABM are still more frequent applications of activitybased techniques than the costing of products or services (Innes et al 2000).

Kaplan has stressed that it is a management system not an accounting system. The ABC system derives its power from the way its outputs can be used for cost management (Cooper and Kaplan, 1992a, Kaplan and Cooper 1998):

“ABC information, by itself, does not invoke actions and decisions leading to improved profits and operating performance. Management must institute a conscious process of organizational change and implementation if the organization is to receive benefits from the improved insights resulting from an ABC analysis.” 
Cost system have been shown to have developed considerably in recent years (Drury and Tayles 2005) and since its introduction in the late 1980's activity-based costing (ABC) has been maintained to be a contribution to costing and cost management with considerable success in the private sector, particularly in service businesses. The public sector is composed to a very great extent of service functions, yet considerably less has been reported of the use of $\mathrm{ABC}$ to support cost management and accounting in this sector. Additionally, somewhat predictably, there has been less publicity given to the failures of cost system development and ABC.

This situation can be extrapolated to Spanish public sector, where town halls are obligated to calculate the cost of services subject to taxation. In this way, town halls must have a cost system in place to calculate the cost of services as precisely as possible, as by law they are banned from making a profit from these. Due to this law, some town halls have tried to develop an ABC system to fulfil these requirements; most of them have failed in the attempt. In this regard, this study analyses the causes of the nonsuccessful implementation of ABC systems in the Spanish public sector.

The structure followed begins with a section about ABC, its development and implementation. This is followed by a discussion of management accounting in the public sector including the situation in Spanish city councils. The research approach and method are dealt with next followed by a presentation and discussion of the findings. Finally we draw some general conclusions about the essential features for successful implementation of ABC information in the Spanish public sector.

\section{System Applications: ABC, ABCM and ABM}

Cost management is a part of an ABC system which includes overhead cost reduction, activity-based cost management, and analysis of non-value-added activities. The performance-improvement applications are used for changing the way things are done in order to achieve, among other things, substantive cost savings in carrying out a business process. 
The surveys conducted by Innes and Mitchell (1995) and Innes et.al. (2000) were significant in the sense that they focused on the differing areas of application of $A B C$ in the UK's largest companies. Findings of these surveys include the fact that cost management applications outweigh the product costing applications which were central to ABC's initial development. The cost reduction and cost control applications of ABC are most popular among its users. ABC users claim that it can change behaviour in the organisations in a wide variety of ways through the impact of information which ABC generates for management decision-making.

Consultants are not insignificant in their authorship of ABC articles (Bjornenak and Mitchell 2000). One group of consultant authors confirms that from their experience there have been significant changes in ABC systems. They summarise these in three different stages-infancy, teens, and adolescence (Ashworth and Evans, 1995).

\section{Organisational, Operational and Behavioral Consequences}

The introduction of $\mathrm{ABC}$ system has directly affected the working procedures or operations within organisations (Friedman and Lyne, 1995). These include the working procedures of management accountants, attitudes and structures within the finance function, relations between finance and operational departments and attitudes and structures in the organisation as a whole.

The introduction of $\mathrm{ABC}$ systems influences how people think, how the work of different organisation members interrelates with each other, and how the organisation is structured. The changes in the way people think and the way they interact will affect the permanence and effectiveness of changes in working procedures or techniques.

In many companies the initiative to introduce the $\mathrm{ABC}$ system is seen as part of a general culture change. The ABC system improves the cost awareness among the staff and managers. ABCM is more specifically aimed at structural change in a business unit. Systems are often being introduced into companies which are in the midst of a significant change programme. 


\section{ABC Implementation}

Several reservations exist constraining the rapid adoption of $A B C$, most important among them are the expected scale, complexity and cost of change involved in design and implementation. Employees reservations about ABC based on suspicions that it would be used to achieve cost reductions through redundancies, and increased accountability; and difficulties in overcoming resistance to change due to cultural reasons.

Both academics and consultants are developing greater knowledge about suitable implementation, this covers both design choices and implementation procedures. Cooper has documented a structured approach to implementation (Cooper and Kaplan, 1992b) which involves making decisions about design choices on the one hand a structured implementation methodology on the other.

Top management commitment is required to ensure the input and co-operation of people from all departments. Lack of commitment sends wrong signals that the new system is not important. Management should determine that employees are ready for the change before implementing the $\mathrm{ABC}$ system. The employees must believe that changes to $\mathrm{ABC}$ will improve matters and for this a pilot project can be carried out, which will quickly demonstrate payoffs to managers and staff.

The implementation team needs to know enough about the theory and practice of ABC so that they can design an appropriate system. The management has to have enough knowledge about the theory of $\mathrm{ABC}$ and its potential benefits so that they can accept and use the findings of the project. The ABC system must become integral to performance evaluation. Failure to include ABC measures in performance evaluation sends the message that it is unimportant and can be assigned a low priority.

Shields and Young $(1989,1994)$ note that ABC systems are administrative innovations rather than technical innovations and should be researched in that wider context. Several studies have been undertaken relating to the success of ABC amongst adopting firms. In the UK Friedman and Lyne (1999) used longitudinal case studies to explore factors influencing ABC success. They found that ABC success was associated with a clearly recognised need for $\mathrm{ABC}$ at the outset, broad based support for it beyond the 
accounting function, and adequate resourcing of the implementation. The survey by Innes et al. (2000) investigated the association between ABC success and top management support, the involvement of consultants, and user involvement in the implementation. Only top management support had a significant impact in explaining ABC success.

A number of the studies relating to the factors influencing ABC success have been undertaken in the USA. Success has been measured by management evaluation (Shields, 1995), use and satisfaction with ABC (Swenson, 1995) and employee satisfaction (McGowan and Klammer, 1997).

Shields (1995) acknowledges the difficulty in defining ABC success, pointing to vagueness in the literature and a failure to achieve consensus about a definition, even after consulting ABC experts. He found that respondents' perception of success was linked to six behavioural and organisational variables: top management support; integration with competitive strategies; performance evaluation and compensation; nonaccounting ownership of the $\mathrm{ABC}$ project; training provided for designing, implementing and using $\mathrm{ABC}$; and the provision of adequate resources.

Building on Shields and Young (1989, 1994), he asserts that:

...consistent with other administrative innovations the successful implementation of a cost management system does not depend on the technical resources, such as whether (or what type of) software is used whether the system is integrated with other accounting systems or stand alone, or whether external consultants are used. (p151)

In his empirical work (Shields 1995), he found no correlation between perceived ABC success and technical variables such as software used, stand-alone system or external consultant (p161). He also pointed to the importance of training in designing, implementing and using $\mathrm{ABC}$, firstly, as an important way to integrate $\mathrm{ABC}$ into the company and, secondly, to provide an opportunity to achieve non-accounting ownership. Shields concluded that the key to successful ABC implementation is effectively dealing with specific behavioural and organisational variables, and that success is more likely when the six variables identified are acknowledged as part of an integrated implementation strategy. Top management support for ABC is very important because 
senior managers can focus resources on activities they deem worthwhile and sideline innovations that they think are not.

Swenson (1995) surveyed 50 financial and operating managers at 25 firms on their satisfaction with $\mathrm{ABC}$ and use of $\mathrm{ABC}$ information to support decisions. The results indicated that participants viewed $\mathrm{ABC}$ as an improvement over their old system; those participants who were more satisfied with their ABC systems were more likely to make use of the $\mathrm{ABC}$ information.

McGowan and Klammer (1997) examined the users’ perceptions of ABC systems covering four research sites. Their findings supported three of the factors identified by Shields (1995) as significantly associated with ABC success (top management support, performance evaluation links and adequacy of training and training resources). In addition, user involvement in implementation and their perception of the quality of the information produced was positively associated with ABC success.

Using data from a sample of 166 firms, Foster and Swenson (1997) examined the effect of using alternative success measures. They concluded that highest explanatory power was found from broad-based ABC success measures and identified potential success measures that have been used in part to guide this study: the use of ABC information in decision making, the decision actions taken with ABC information, and the dollar improvement resulting from ABC.

\section{ABC Problems}

As more organisations and researchers have gained experience of $A B C$, practical problems in implementation are variously discussed and criticisms have emerged (Cobb et.al. 1992; Cooper et al. 1992; Connolly and Morrow 1994; Friedman and Lyne 1995; Malmi 1997).

Some early tentative observations on ABC have been confirmed by the results of later studies. The implementation of $\mathrm{ABC}$ systems requires a major change that involves disruption and commitment of resources over a substantial period of time (Innes and 
Mitchell, 1991). The costs of ABC may be relatively high and therefore the benefits have to be substantial for it to be worth adopting (Staubus, 1990).

Data collection problems are associated with cost driver data about the individual product or services. It is a complicated process to determine the appropriate activities and cost drivers and to collect this data. Additionally, the existing accounting information system may not be in a suitable form for ABC analysis.

The amount of work involved applies both to the design team and the accountants implementing it. Generally more than one interview is required with managers to agree the definition of activities and the amount of resources being devoted to each activity. Some activities cross departmental boundaries and this requires co-ordination of information from many interviews to determine the major activities.

Several members of the implementation team take interviews and collect data, so consistency is required in their approach. Project team members should be clear about what they are costing and how it is defined. There should be consistency in costing and level of details required for data.

The non-focus of senior managers and implementation team on specific business issues may lead to failure of the project. The companies who adopted this system without any clear perceived need may meet with negative results. As the company is not ready for the implementation and staff think that the new system is being imposed on them so they do not develop any commitment to it. Sometimes there is need for an ABC system but this is not being communicated well by senior management to the managers and staff of the company (Friedman and Lyne, 1995).

Most organizations experience some degree of delay in implementation of ABC systems which causes inconvenience. There are many sources of delay, for example, financial crisis, pressure of work, and some times other priorities. After deciding the focus of project, it is important to consider how quickly ABC should be introduced. A pilot approach can be adopted. The benefits of this approach are that it enables the approach adopted to be tested and, if necessary, modified; and it allows some early outputs to be achieved. 
Employee resistance is a major obstacle in implementation of ABC system. Such resistance is natural as the most common objective of the ABC system is to effect a reduction in overhead costs, and in almost all circumstances this will involve a reduction in personnel. And after having been downsized, TQMed, and reengineered, managers and non-managers alike often greet $\mathrm{ABC}$ as the latest threat to their jobs.

The resistance to $\mathrm{ABC}$ system comes from either accounting or non-finance functions and some times from both. Any initiative to introduce the new system from outside the accounting department is opposed by accountants as they are used to old system and they do not believe that new system will dramatically change the definition of success and failure. Similarly, the non-financial personnel do not like the interference and suggestions about operations from the accounting department.

It has been shown there is considerable literature about the uses or non use of cost systems. There are very few references about this topic applied to Public sector and even less in the Spanish literature. As Garcia Alegre (2000) observes: "Costing and ABC costing in Spanish Public sector are not solved yet”

\section{Spanish Public Sector}

In Spain, cost systems are essential for town halls in that they are obliged to calculate the cost of the services subject to taxation (waste collection, etc). Town halls must have a cost system in place to calculate the cost of services as precisely as possible, as by law they are banned from making a profit from these. The service cost must be equal to or less than the tax collected.

Much cost information is needed to fulfill legal requirements and to help the decisionmaking process. It would seem logical therefore, to expect that town halls have developed cost calculation systems. The reality is generally not so, some statistical data and studies show that (Garcia Alegre 2000) not more than $40 \%$ of the Catalonian Town Halls over 50.000 inhabitants had presented the legal information about the cost and performance of the services subject to taxation. Of this $40 \%$, less than $10 \%$ use a 
minimum development model of calculation. This calculation of costs is undertaken to comply with the most basic legal requirement that should be complied and is not in a form of information that helps to improve the management and decision making process of the organisation.

The paper attempts to address this shortcoming in management accounting systems development in Catalan town halls. Three related enquiries have been undertaken:

- An empirical study (survey) of Catalan town halls of towns of over 20,000 inhabitants to find out the common practices in management accountancy, including the degree of development of the management accounting tools used.

- A case study analysing the costing and ABC model of one Catalan Town Hall. This is the only known Catalan town council that has managed to successfully introduce an ABC-type cost model. In addition to describing the model itself, through 28 interviews with users of the information derived there from, (public managers and the individuals in charge of introducing and designing it) the key factors as to why the model has been successful in the organisation are identified.

- An empirical study (survey) of the remaining Catalan town halls to find out the reasons for the extremely modest development of cost systems, including the non-successful development of $\mathrm{ABC}$, despite the existing regulations requiring some cost analysis.

In particular the last two elements enable the research to answer in a reasonably robust manner what are the key factors of success or failure regarding implementation of a cost system in a Town Hall?

\section{Research Methodology}

Considerable $A B C$ research has taken place during the last decade using both case studies and surveys. The use of case studies is recommended by Kaplan (1986) as a method of exploring interesting phenomena in accounting. Scapens (1990) sees case 
studies as a way to understand management accounting practices and the factors that influence them in a business context. The researcher is encouraged to 'mess about in mucky problems'. Spicer (1992) provides a developed discussion of case studies in the context of the development of contemporary research in management accounting.

In this research a mixed approach is taken, in that after initial interviews with managers in one municipality, a survey was used to capture the views of managers in others. This was seen as an appropriate means to identify and confirm, at this stage, managers' opinions as users of the system and as a possible precursor to initiate corrective action based on the results. The research originated based on interviews with managers in both accounting and non-accounting in one municipality within Catalonia. The interviews all made use of non-directive questioning with the aim if discovering the views of the managers involved. Based on a discussion of results of the interviews, they were followed up by questionnaires addressed to representatives of 53 other Catalonian towns.

\section{Findings and Discussion}

\section{Management Accounting Practices In Catalan Town Halls.}

To obtain an overview of management accounting systems in town halls a short survey was despatched to 53 representatives of Catalonian town halls. There were 21 usable replies. From these, examining town hall cost calculation systems and analysing their technical development, the conclusion is that on the municipal level there are basically two different cost calculation systems whose methods can be outlined in the two figures below. 


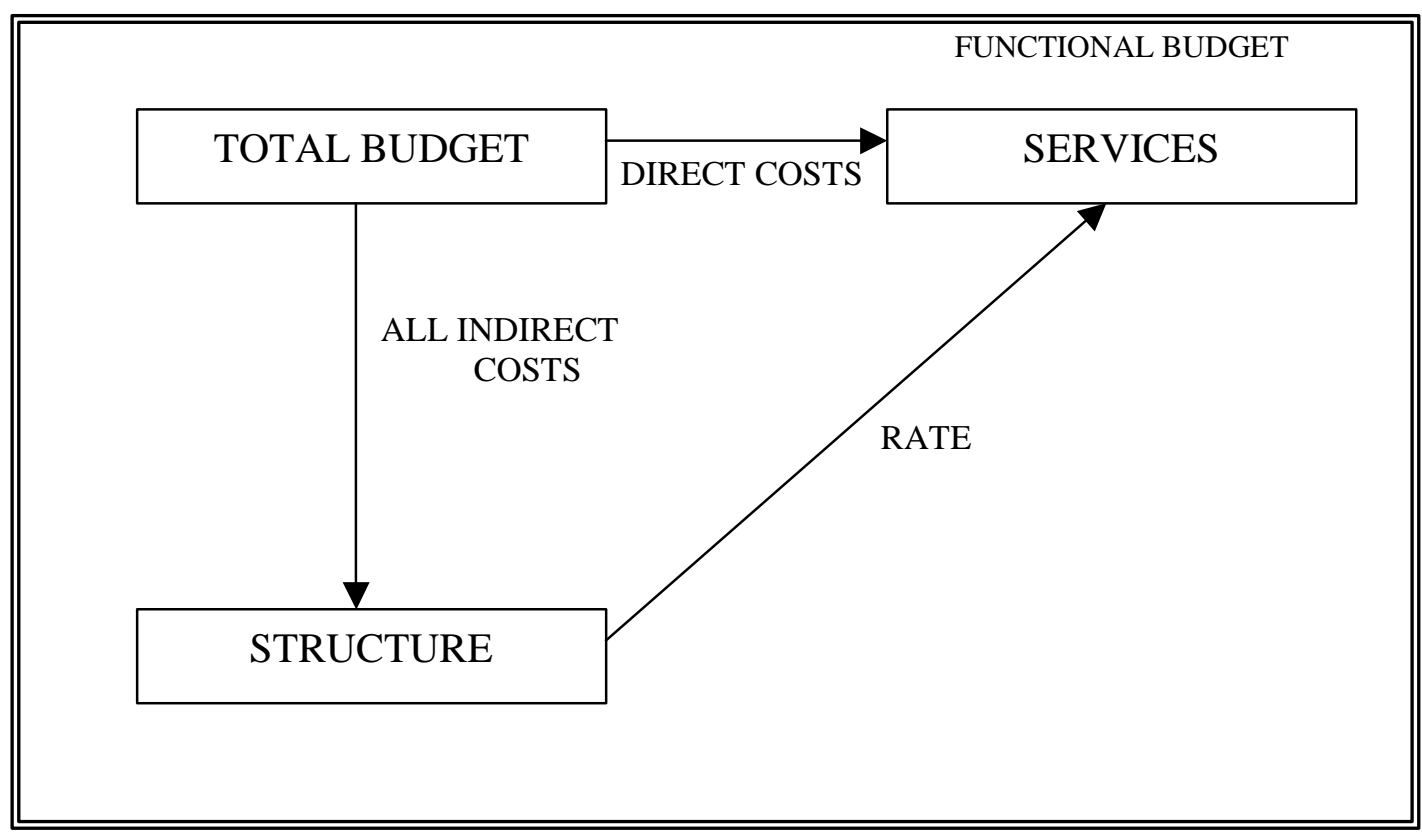

Figure 1. Main cost methodology used by Catalonian Town Halls.

Figure 1 shows the cost calculation method most commonly used in town halls. Its starting point is the total budget of the city council, splitting it in two big groups: direct and indirect costs. The first group, direct costs, is allocated to the services according to the functional budget. The functional budget is a standardized management tool of the Spanish Public Sector, which is used to capture how the municipal funds are allocated to support different public services (waste collection, police, street lighting, sports centres etc.). In that way, the result is that all the city councils are actually calculating the estimated direct costs of all the services they are providing to the citizens. Benchmarking can be used to measure the efficiency in the management of these services. The indirect costs are allocated into a general cost centre called "structure”, which in then apportioned amongst the services according to a flat rate (direct costs of the service / total direct costs). The result of this flat rate of tax is that those services which uses more direct cost, are receiving more indirect cost. This has two very important weaknesses:

$\checkmark$ The entire municipal budget is considered a cost (including investment line items or payments on debt capital).

$\checkmark$ The indirect cost allocation is not appropriate. Given the heterogeneity of the services, the heavy proportion of indirect costs over total costs and the different options for service provision (direct provision, concessions...), the allocation 
base is potentially highly misleading for costing and cost management, a more refined allocation criterion appears to be desirable.

As a result of these weak points, the information generated from the model is not very useful and is biased, which is particularly serious if taxes and prices are set based on this method. The fact that the managers and users of the system perceive that the information from the system is biased and not very useful might also influence the scant interest shown (by some town halls) in using these management tools.

Figure 2 shows the second most popular method followed by Catalan town halls to calculate the costs of services for citizens. In this figure it can be seen that as in the previous methodology, the starting point is the total budget, and the functional budget is still used to accumulate the direct costs of the services. The difference, however, is that there is a relationship with the organic budget (by areas). This methodology is an improvement on the previous one in the sense that there is not a single centre accumulating indirect costs rather different ones are used related to the different services provided. In this way, the second method of indirect cost allocation is claimed to be an improvement, although there is still the problem of passing on an area's indirect costs to the services it provides.

In Catalan town halls (especially in municipalities of 20,000 to 50,000 inhabitants) there is widespread use of cost centres, which compromises the calculation of the cost objective when the weight of the indirect costs is high and when there is great heterogeneity among the objectives. Therefore, one of the problems detected is the lack of a cost system adapted to the peculiarities of the town halls. 


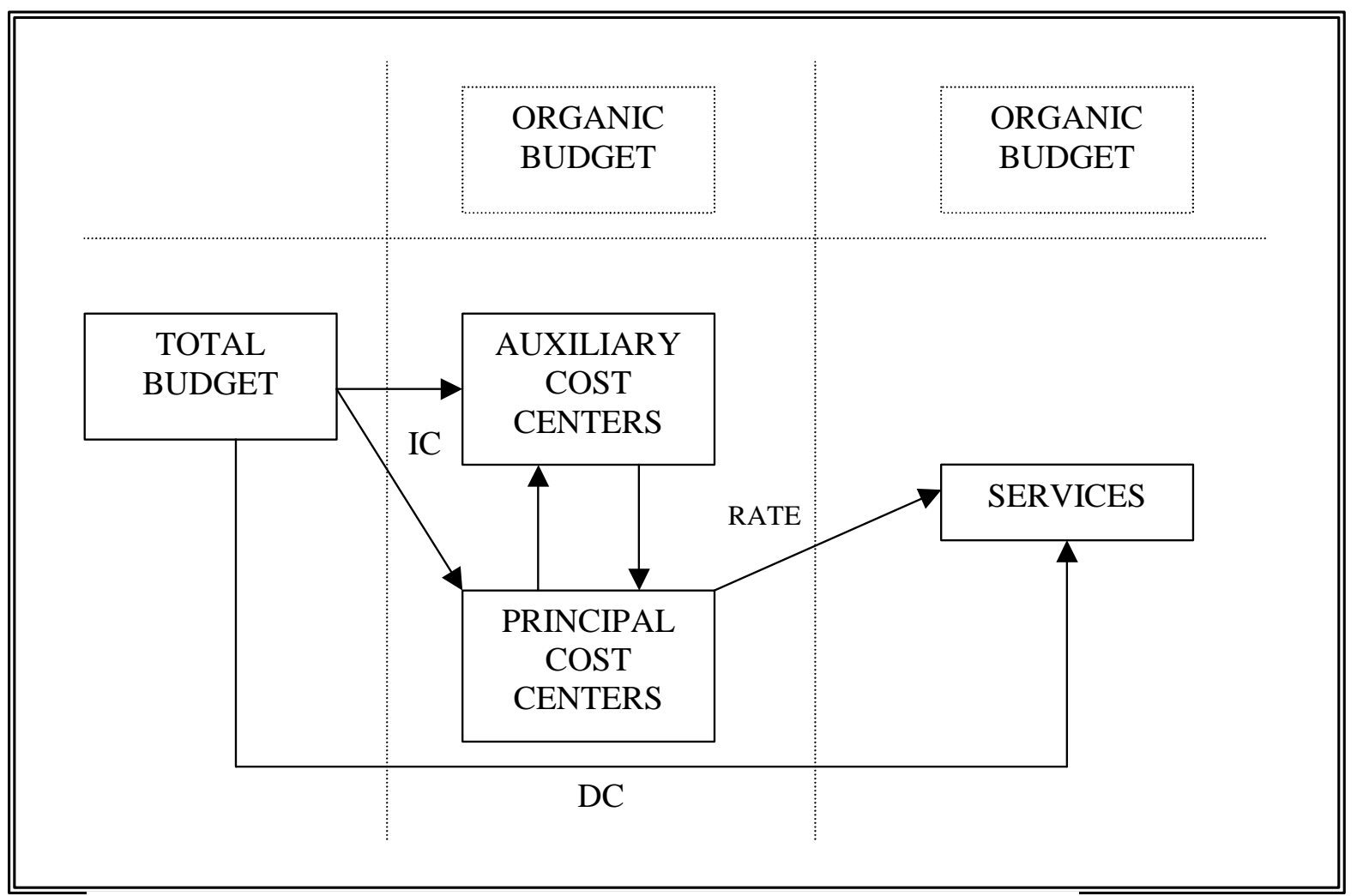

Figure 2. Alternative cost methodology used by Catalonian Town Halls.

In addition to these methodological problems, there is also a lack of interest in or resources for evolving an improved methodology. The cost models are over ten years old in 55\% of the respondents, and over five and under ten years old in 35\%. This shows that the town halls made attempts to adapt to the 1988 law regulating Local Tax Offices, but that this interest in improving their management tool has waned over time. For example $60 \%$ of town halls have made no change to their cost system since it was first introduced, and the average score given by town halls in terms of satisfaction with their cost system is 4.4 (on a scale of 1-10). Therefore, the town halls are fully aware that there is room for improvement.

It appears that the cost systems are not the main management accounting tool in town halls; rather, as expected, the budget is. However, the budget is not used as a tool to improve management but as a tool to control public funds.

One of the main functions of the budget is making comparisons with the actual spend by calculating deviations (variances). If improved management were pursued, this would have to take place just after the service or the activity, as if we wait for the budget closure to 
calculate the differences, this information could only be used for the process of preparing the budget for two years hence (remember that the municipal budgeting process begins in September, before the budget is closed). The fact is that very few town halls calculate the deviations immediately after the service or activity, which demonstrates that the budget is more a tool for calculating the allocation of public funds than a tool for improving management. There is no basis in the system currently used to identify cost reduction or performance improvement programmes. The survey confirmed that the deviation calculation is not generally used to monitor actions or take corrective measures, fact confirmed by $55 \%$ of respondents.

The fact is that hardly any town halls have a cost system that allocates indirect costs with any reasonable degree of accuracy. This means that the services suffer from serious over-costing or under-costing on a regular basis. This inefficiency means that the public sector spending is generally rising and on a national scale is harming the Spanish economy.

The overall conclusion of this brief survey is that a lot remains to be accomplished not only on the technical level and in the development of management tools, but also especially in changing of certain managers' mindset as regards the usefulness of these tools and their positive influence on improving citizen-focused, efficient management. A case study of one municipality which had successfully improved the cost system it employed is now presented.

\section{The Study of Successful ABC}

One municipality worked to improve the sophistication of their costing system which had all the characteristics of an ABC approach. It was concluded that this could be the basis of extending the current work and use a case study of this organisation as a platform. This study consisted of 28 semi-structured interviews where different decision-makers in the town hall were questioned on their overall opinions of the model being applied, the usefulness of the information derived from it, the validity of this information, their degree of knowledge about this model and, the key variables behind the success or failure of the model. This case study will enable us to identify certain factors, both those internal and those from the environment (organisational, individual behaviour and technical), which are necessary to ensure the success of the introduction 
of a cost system in a town hall.

Three major groups of variables will be highlighted:

1. Technical variables

2. Organisation-related variables

\section{Variables related to individual behaviour}

All interviewees were questioned about the cost system in their municipality and the characteristics of its implementation. This was through non-directive questioning their responses were analysed to reveal the number of times that certain aspects were mentioned. A content analysis was undertaken and Annexe 1 was constructed from and shows the results of these interviews. The \% indicates the emphasis given by respondents (based on the number of time they were mentioned in interviews) who consider the variable to be key to the success of the implementation of the costing model. The most important findings in this study were:

1. The variables related to the organisation are those that acquire a greater relevance in the success of the cost system in the City council concerned. According to managers and users opinion, variables like the support from politicians (89\%) and techniques (86\%), and resources ${ }^{4}$ available for introducing the system (96\%) affect the success of the model in the organization remarkably. Some variable that are important in the Private Sector like size of the organization (11\%) and the existence of a long term strategy or action plan (11\%) are less important.

2. Fear of change (89\%), the perception of the usefulness of the model and its information (79\%) and the perception of the cost model more as a tool to monitor people than as a management tool (96\%), are variables related to the individual behaviour that are most important in the success of the tool. Other variables detected were the perception of the impact of the model on the

\footnotetext{
${ }^{4}$ Like "resources” we have understand "human resources" (personnel, consultants...) and "economic resources” (available funds).
} 
organization (75\%), the average age of the $\operatorname{staff}^{5}(43 \%)$ and the level of user training $(71 \%)^{6}$.

3. Talking about technical variables, we have to say that is the less important group. Only three variables related to the system were detected and none was scored over $70 \%$. According to interviewees the model and variables related to the model are less important than variables related to the organization and variables related to the individual behaviour. The succes of the tool in a town hall requires two basic things:

"support of the higher management and a previous work of awareness and explanation of the convenience of the tool for the organization”

In this case study 17 variables have been detected that influence the success or non success of a cost system in the municipality. These factors are now used as variables to contrast in the survey that is developed for other in the following section.

\section{The Reasons for the Low Degree of Development of Cost Systems in Catalonian Town Halls}

Following the initial enquiry at the single town hall the enquiry sought to explore further the reasons behind the current status (the scant development) of cost systems in town halls. This survey was addressed to town halls where attempts had been made to implement improved cost systems on ABC lines but these had stalled or failed.

\footnotetext{
${ }^{5}$ According to managers and users opinion: the lower average age the greater probability of implanting the system successfully (more receptive to accept new management tools).

${ }^{6}$ According to managers and users opinion: more level of training greater probability of implanting the system successfully (more receptive to accept new management tools).
} 


\begin{tabular}{|c|c|}
\hline Factor & Score \\
\hline $\begin{array}{l}\text { 1. Existence of a parallel system. Non-abandonment of the former cost system } \\
\text { until the new model is fully implemented. }\end{array}$ & 3.4 \\
\hline 2. Timeframe in which the model was implemented. & 3.9 \\
\hline 3. Complexity of the model. & 6 \\
\hline 4. Size of the organisation. & 3.1 \\
\hline 5. Resources available for introducing the system. & 9.6 \\
\hline 6. Percentage of indirect costs. & 8.4 \\
\hline 7. $\quad$ Organisation management structure. & 6.2 \\
\hline 8. Existence of a long-term strategy or action plan. & 3.4 \\
\hline 9. Support for the model from key political positions. & 9.8 \\
\hline 10. Support for the model from key technical positions. & 9.7 \\
\hline 11. Levels of user training. & 5.8 \\
\hline 12. Awareness training sessions prior to implementation. & 3.7 \\
\hline 13. Perception of the usefulness of the model and its information. & 7.1 \\
\hline 14. Average age of the staff. & 7 \\
\hline 15. Fear of change. & 8.2 \\
\hline 16. Perception of the impact of the model on the organisation. & 7.1 \\
\hline $\begin{array}{l}\text { 17. Perception of the cost model more as a tool to monitor people than as a } \\
\text { management tool. }\end{array}$ & 8.3 \\
\hline
\end{tabular}

Table 1. Variable score table. Opinion of managers responding to the survey.

In particular, six variables have been found that are extremely important (most scored items, see table 1) and which must be borne in mind if management wish to successfully introduce and use a cost system in a town hall. As a result of the study of these variables and the behaviour between them (annexe 2), a model has been defined of the characteristics needed to achieve an efficient cost system that is not rejected by the organisation.

The trends in this model could be divided into two clearly distinct parts: first, the model must be publicly supported by politicians and technicians (figure 3), and the entire organisation must be aware of this support from the time the model is introduced until it is fully established. This support must not be just lip service; it must also be expressed in resources (monetary, human, ...). 


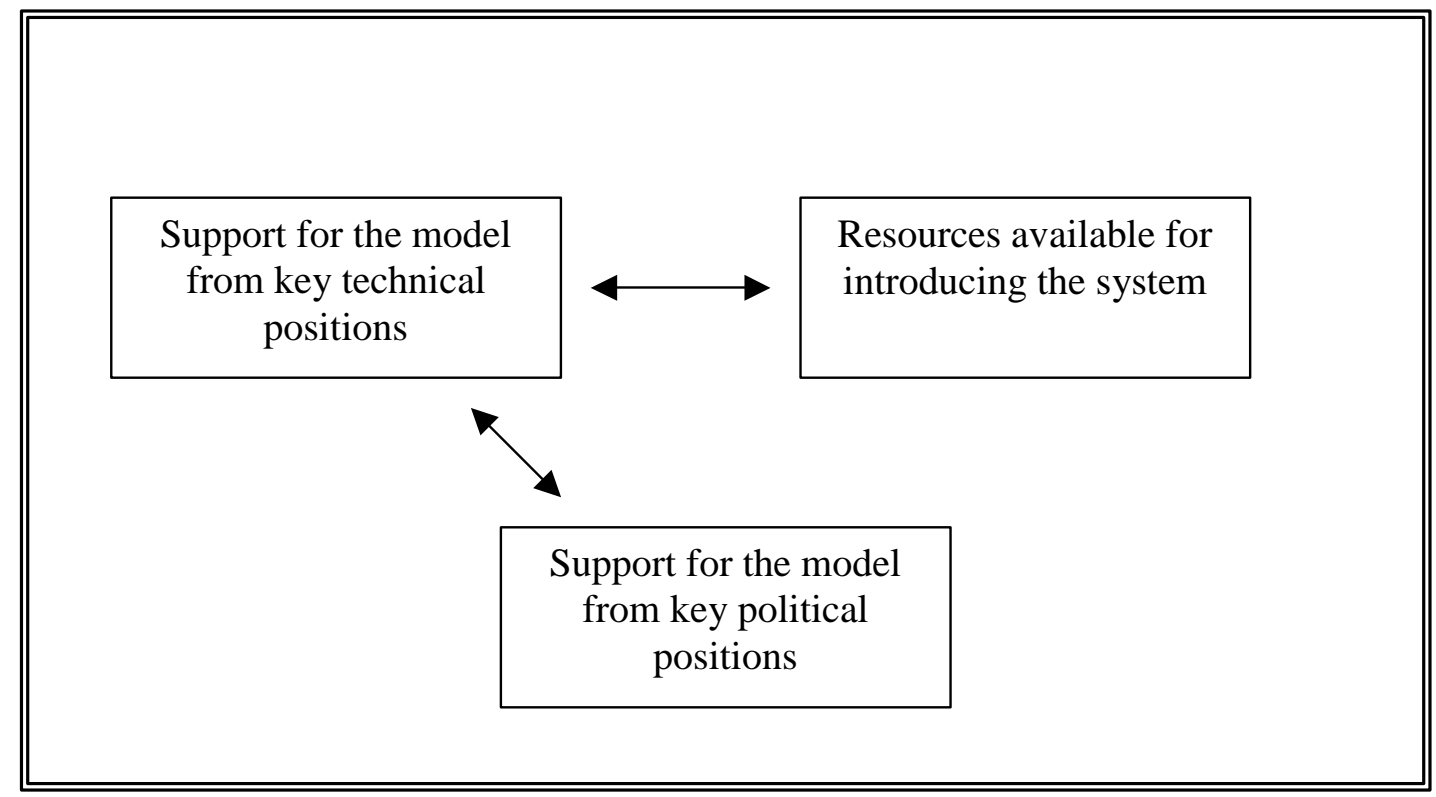

Figure 3. Key implementation issues - organisational.

Secondly, the organisation's fear of change must be overcome (figure 4). One of the ways to do this is to stress that a cost calculation system is not a tool for monitoring people but a tool that, when used properly, enables the management to improve. If we stress that this tool is useful, we will overcome this fear. However, in organisations where the average age of the staff is higher, there will be a greater fear of change and less willingness to adopt the tool.

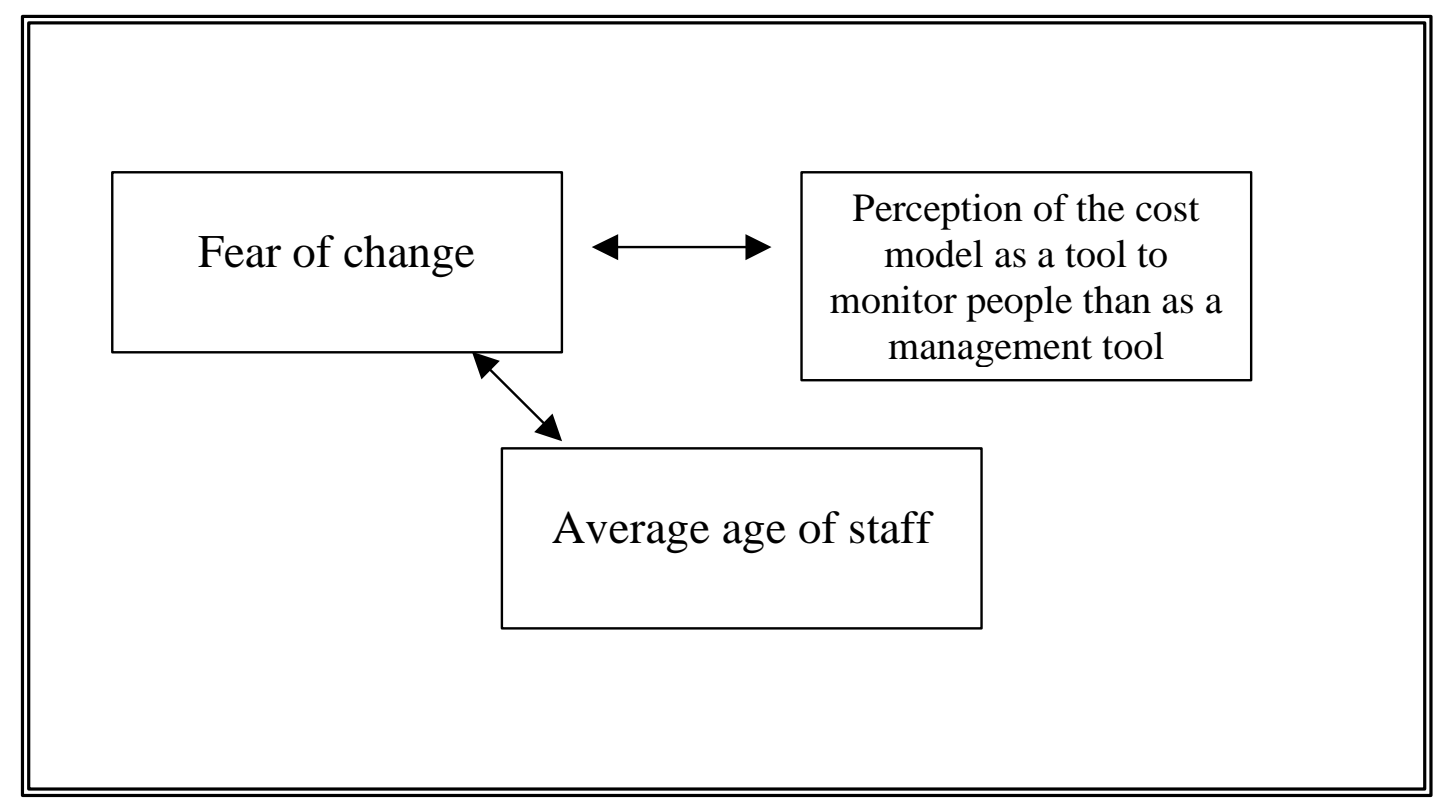

Figure 4. Key implementation issues - Individual.

In this section, Catalan town hall cost systems have been shown to be underdeveloped, particularly if there is a lack of interest from politicians, which translates into a significant 
lack of resources for introducing any management tool. Another of the problems shown is that the fear of change has not been overcome, and we even find public managers who believe that cost systems are of little interest. These are the reasons the cost systems in town halls have failed to be developed and accepted. 
Ashworth, G. And Evans, H. (1995) Activity Based Management : Moving Beyond Adolescence Management Accounting (U. K.), December, Pp. 26-30.

Bjornenak, T. 1997. Diffusion and Accounting: The Case of ABC in Norway. Management Accounting Research 8: 3-17.

Bjornenak, T. and Mitchell, F. (2000)A Study of the Development of Activity Based Costing Journal Literature 1987- 1998. Paper presented at the EAA Conference Muich, Germany.

Bell, A. T. And Mecimore C. D. (1995) Are We Ready For Fourth-Generation ABC? Management Accounting (U. S. A.), January, Pp. 22-26.

Cobb, J., Mitchell, F. And Innes, J. (1992) Activity Based Costing : Problems In Practice. London Chartered Institute Of Management Accountants.

Connolly, T. And Morrow, M., (1994) Practical Problems Of Implementing ABC. Accountancy, January, pp. 76-74.

Cooper, R. (1996) The Changing Practice Of Management Accounting. Management Accounting (U. K.), March, Pp. 26-35.

Cooper, R. and Kaplan, R. S. (1992a) Activity Based Systems : Measuring The Costs Of Resource Usage. Accounting Horizons, Sept., Pp. 1-13.

Cooper, R. and Kaplan, R. S. (1992b) The Design Of Cost Management Systems. Englewood Cliffs, Nj, Prentice Hall.

Cooper, R., Kaplan, R. S., Maisel, L., Morrissey, E. And Oehm, R. (1992)

Activity Based Cost Management : Moving From Analysis To Action.

Montavle, NJ, Institute Of Management Accountants.

Drury, C. And Tayles, M. (2000) Cost systems Design and Profitability Analysis in UK Companies, London, Chartered Institute Of Management Accountants.

Drury, C. and Tayles, M., Explicating the Design of Overhead Absorption Procedures in UK Organisations. British Accounting Review,Vol 37, 1, 2005 47-84.

Foster, G and Svenson, D. W. 1997. Measuring the Success of Activity Based Cost Management and its Determinants. Journal of Management Accounting Research 9: 109-142.

Friedman, A. L. And Lyne, S. R. (1995) Activity Based Techniques : The Real Life Consequences. London : Chartered Institute Of Management Accountants.

Friedman, A. L. And Lyne, S. R. (1999) Success and Failure of Activity Based Techniques London : Chartered Institute Of Management Accountants.

García Alegre, E. (2000): “La determinación de los costes de los servicios públicos. ¿Un problema de càlculo o de gestión?”. Revista Auditoría Pública, n 20. Pag 20-32. 
Holton, M. (1999) Implementing ABC in a Service driven Business- DHL Worldwide. In Innes (Ed) Handbook of Management Accounting Gee London

Innes, J. And Mitchell, F. (1990a) The Process Of Change In Management Accounting : Some Field Study Evidence. Management Accounting Research, Vol. 1, Pp. 3-19.

Innes, J. And Mitchell, F. (1990b) Activity Based Costingt : A Review With Case Studies. London : Chartered Institute Of Management Accountants.

Innes, J. And Mitchell, F. (1995) A Survey Of Activity-Based Costing In The U. K.'S Largest Companies. Management Accounting Research, Vol. 6, Pp. 137-153

Innes, J. Mitchell, F. and Sinclair, D. (2000) Activity-Based Costing in the UK's Largest Companies: a comparison of 1994 and 1999 survey results. Management Accounting Research (11) pp 349-362.

Johnson, H. T. (1988) Activity Based Information : A Blue Print For World-Class Management Accounting. Management Accounting (U. S. A.), June, Pp. 23-30.

Johnson, H.T. 1992. Relevance Regained New York: Free Press.

Kaplan, R.S. (1986) The Role for Empirical Research in Management Accounting, Accounting Organisations and Society, Vol.11, No.4/5, (pp 429-452)

Kaplan, R.S. and Cooper, R. (1998), Cost and Effect: Using integrated systems to drive profitability and Performance, Harvard Business School Press.

Kleinsorge, I. K. And Tanner R. D. (1991) Activity Based Costing : Eight Questions To Answer Before You Implement Journal Of Cost Management, Fall, Pp. 84-88.

McGowan, A.S. and Klammer, T.P. 1997. Satisfaction with Activity-Based Cost Management Implementation. Journal of Management Accounting Research 9: 217-238.

Malmi, T. 1997. Towards Explaining Activity-Based Costing Failure: Accounting and Control in a Decentralised Organisation. Management Accounting Research 7: 459-480.

Scapens, R.W. (1990) Researching Management Accounting Practice: The Role of Case Study Methods, British Accounting Review, Vol. 22, (pp 259-285).

Shields, M. 1995. An Empirical Analysis of Firms’ Implementation Experiences with Activity Based Costing Journal of Management Accounting Research 7: 1-28.

Shields, M. D. and S. M. Young (1994). Behavioural and Organisational Issues in Management Accounting, B.Brinker (Ed.). New York, Warren Graham Lamont.

Swenson, D., 1995. The benefits of activity-based cost management to the manufacturing industry, Journal of Management Accounting Research, Vol.7, Fall, 167180.

Spicer B.H. (1992) The Resurgence of Cost and Management Accounting: A Review 
of some recent developments in Practice, Theories and Case Research Methods, Management Accounting Research, Vol 3 pp 1-37.

Staubus, G. J. (1990) Activity Costing : Twenty Years On Management Accounting Research, Vol. 1, Pp. 249-264.

Turney, P.B.B., and Anderson, B., "Accounting for Continuous Improvement", Sloan Management Review, Winter 1989, pp37-47. 


\begin{tabular}{|c|c|}
\hline Factor & $\%$ \\
\hline $\begin{array}{l}\text { 1. Existence of a parallel system. (Non-abandonment of the former cost } \\
\text { system until the new model is fully implemented). }\end{array}$ & $36 \%$ \\
\hline 2. Timeframe in which the model was implemented. & $64 \%$ \\
\hline 3. Complexity of the model. & $50 \%$ \\
\hline 4. Size of the organisation. & $11 \%$ \\
\hline 5. Resources available for introducing the system. & $96 \%$ \\
\hline 6. Percentage of indirect costs. & $79 \%$ \\
\hline 7. Organisation management structure. & $86 \%$ \\
\hline 8. Existence of a long-term strategy or action plan. & $11 \%$ \\
\hline 9. Support for the model from key political positions. & $89 \%$ \\
\hline 10. Support for the model from key technical positions. & $86 \%$ \\
\hline 11. Levels of user training. & $71 \%$ \\
\hline 12. Awareness training sessions prior to implementation. & $54 \%$ \\
\hline 13. Perception of the usefulness of the model and its information. & $79 \%$ \\
\hline 14. Average age of the staff. & $43 \%$ \\
\hline 15. Fear of change. & $89 \%$ \\
\hline 16. Perception of the impact of the model on the organisation. & $75 \%$ \\
\hline $\begin{array}{l}\text { 17. Perception of the cost model more as a tool to monitor people than as a } \\
\text { management tool. }\end{array}$ & $96 \%$ \\
\hline
\end{tabular}

\footnotetext{
${ }^{7}$ The \% indicates the emphasis given by respondents (based on the number of time they were mentioned in interviews) who consider the variable to be key to the success of the implementation of the costing model.
} 


\section{ANNEXE 2. CORRELATION TABLE}

\begin{tabular}{|c|c|c|c|c|c|c|c|c|c|c|c|c|c|c|c|c|c|}
\hline & 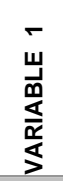 & 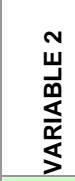 & 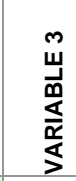 & 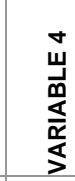 & 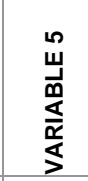 & 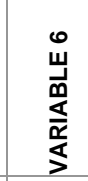 & 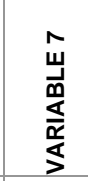 & 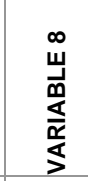 & 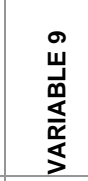 & 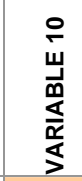 & 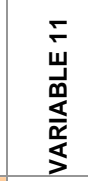 & 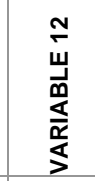 & 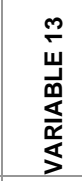 & 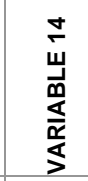 & 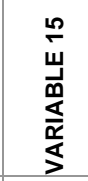 & 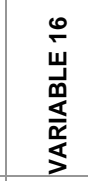 & 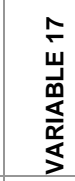 \\
\hline \multicolumn{18}{|l|}{ VARIABLE 1} \\
\hline VARIABLE 2 & & 1,00 & 0,28 & 0,36 & $-0,49$ & 0,21 & $-0,08$ & 0,20 & $-0,15$ & $-0,46$ & $-0,11$ & 0,58 & $-0,11$ & 0,47 & 0,41 & $-0,03$ & 0,17 \\
\hline VARIABLE 3 & & & 1,00 & 0,25 & $-0,24$ & 0,32 & $-0,18$ & $-0,01$ & 0,29 & 0,03 & $-0,16$ & 0,52 & $-0,06$ & 0,15 & 0,41 & 0,29 & 0,48 \\
\hline VARIABLE 4 & & & & 1,00 & 0,20 & 0,15 & 0,11 & 0,42 & $-0,10$ & 0,12 & $-0,19$ & 0,54 & 0,02 & 0,01 & 0,04 & 0,12 & 0,31 \\
\hline VARIABLE 5 & & & & & 1,00 & $-0,21$ & 0,38 & 0,14 & 0,22 & 0,78 & 0,13 & $-0,32$ & $-0,13$ & $-0,23$ & $-0,11$ & $-0,15$ & 0,09 \\
\hline VARIABLE 6 & & & & & & 1,00 & $-0,33$ & $-0,24$ & 0,22 & 0,04 & $-0,38$ & 0,39 & 0,43 & $-0,28$ & $-0,14$ & $-0,23$ & 0,06 \\
\hline VARIABLE 7 & & & & & & & 1,00 & 0,64 & $-0,04$ & 0,27 & 0,67 & $-0,18$ & $-0,05$ & 0,36 & 0,49 & 0,23 & 0,44 \\
\hline VARIABLE 8 & & & & & & & & 1,00 & $-0,13$ & 0,04 & 0,26 & 0,17 & $-0,06$ & 0,13 & 0,19 & 0,09 & 0,21 \\
\hline VARIABLE 9 & & & & & & & & & 1,00 & 0,75 & $-0,23$ & $-0,02$ & 0,26 & 0,03 & 0,15 & 0,20 & $-0,15$ \\
\hline VARIABLE 10 & & & & & & & & & & 1,00 & $-0,05$ & $-0,24$ & 0,14 & $-0,15$ & 0,00 & $-0,01$ & $-0,03$ \\
\hline VARIABLE 11 & & & & & & & & & & & 1,00 & $-0,55$ & $-0,33$ & 0,46 & 0,57 & 0,24 & 0,49 \\
\hline VARIABLE 12 & & & & & & & & & & & & 1,00 & 0,16 & $-0,01$ & 0,07 & 0,22 & 0,25 \\
\hline VARIABLE 13 & & & & & & & & & & & & & 1,00 & $-0,29$ & $-0,37$ & $-0,08$ & $-0,20$ \\
\hline VARIABLE 14 & & & & & & & & & & & & & & 1,00 & 0,81 & 0,38 & 0,35 \\
\hline VARIABLE 15 & & & & & & & & & & & & & & & 1,00 & 0,50 & 0,66 \\
\hline VARIABLE 16 & & & & & & & & & & & & & & & & 1,00 & 0,43 \\
\hline VARIABLE 17 & & & & & & & & & & & & & & & & & 1,00 \\
\hline
\end{tabular}

